\section{Abstract}

\section{Keywords}

\title{
Reliability of cold-formed steel framed shear walls as impacted by variability in fastener response
}

\author{
G. Bian ${ }^{\mathrm{a}}$, A. Chatterjee ${ }^{\mathrm{b}}$, S.G. Buonopane ${ }^{\mathrm{c}}$, S.R. Arwade ${ }^{\mathrm{d}}$, C.D. Moen ${ }^{\mathrm{e}}$, B.W. Schafer ${ }^{\mathrm{f}}$
}

\begin{abstract}
The objective of this paper is to examine the reliability of cold-formed steel framed shear walls with a particular emphasis on walls sheathed with wood structural panels. A sheathed cold-formed steel framed shear wall is a system consisting of studs, tracks, and sheathing often with bridging and/or blocking, connected with steel-to-steel and sheathing-to-steel fasteners. The shear walls may be integrally connected to foundations, floors, or other shear walls through a variety of means including hold downs, straps, diaphragm chords and collectors. Shear wall lateral resistance in cold-formed steel framed buildings varies because of the randomness in the components and connections that comprise the wall. The interaction between fasteners and sheathing is particularly important because (1) sheathing-to-steel fastener response is the main source of shear wall nonlinearity (2) there is high variability in this fastener response. Although the nominal strengths for different shear wall configurations are stated in current design specifications (e.g., AISI S400), variability of shear walls has not been explicitly considered. Existing resistance factors are extrapolations from steel diaphragm testing. To explore the impact of fastener response variability on shear wall reliability, Monte Carlo simulation of typical cold-formed steel framed wood sheathed shear walls with random fastener input was conducted. Variability in fasteners was determined based on existing physical fastener tests. Statistical properties of shear wall strength, demand capacity ratio of key fasteners, as well as relations between fastener strength and shear wall strength are all explored. Reliability evaluation is provided for four different design methods. The results indicate that shear wall strength benefits from a system effect whereby variability in fastener response is reduced through redistribution resulting in reduced variability in overall shear wall strength. Concomitant with this is a slight decrease, approximately $3 \%$, in the mean system strength that also must be considered.
\end{abstract}

cold-formed steel, shear wall, fastener-based simulation, reliability, system reliability

a. Graduate Research Assistant, Department of Civil Engineering, Johns Hopkins University, Baltimore, MD, USA <bian@jhu.edu >

b. Graduate Research Assistant, Department of Civil \& Environmental Engineering, Virginia Tech, Blacksburg, VT, USA < aritrac1@ vt.edu>

c. Associate Professor, Department of Civil and Environmental Engineering, Bucknell University, Lewisburg, PA, USA <sbuonopa@bucknell.edu>

d. Professor. Department of Civil and Environmental Engineering, University of Massachusetts Amherst, Amherst, MA, USA <arwade@umass.edu>

e. Associate Professor, Department of Civil \& Environmental Engineering, Virginia Tech, Blacksburg, VT, USA <cmoen@vt.edu>

f. Professor, Department of Civil Engineering, Johns Hopkins University, Baltimore, MD, USA <schafer@jhu.edu > 


\section{Introduction}

Cold-formed steel (CFS) structural systems are commonly used for low and mid-rise

35 construction. In the design of CFS-framed buildings, shear walls are typically used to

36 provide lateral resistance for seismic or wind load (e.g., see Figure 1). Commonly, wood

37 sheathing, such as oriented strand board (OSB), is screw-fastened to CFS studs and tracks

38 to develop lateral shear stiffness and strength (e.g., see Figure 2).

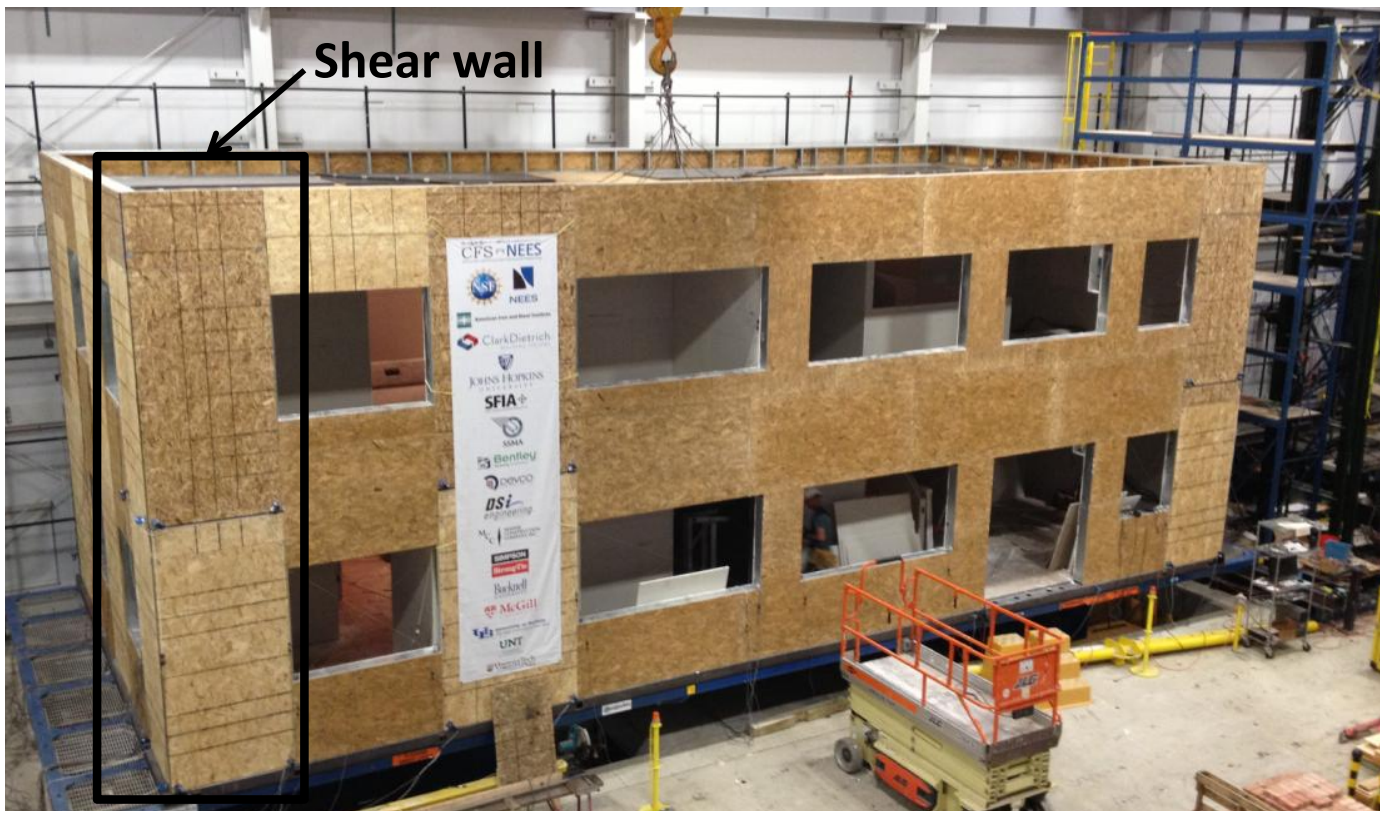

Figure 1 CFS-NEES building and shear wall in it

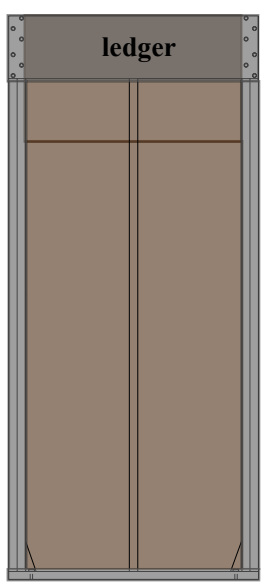

(a) interior view

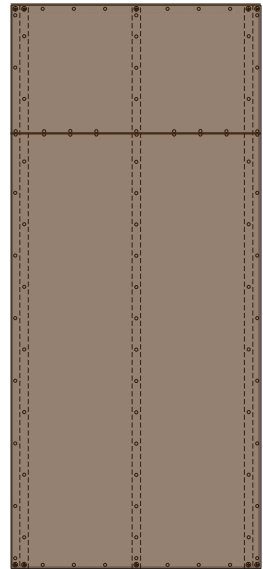

(b) exterior view

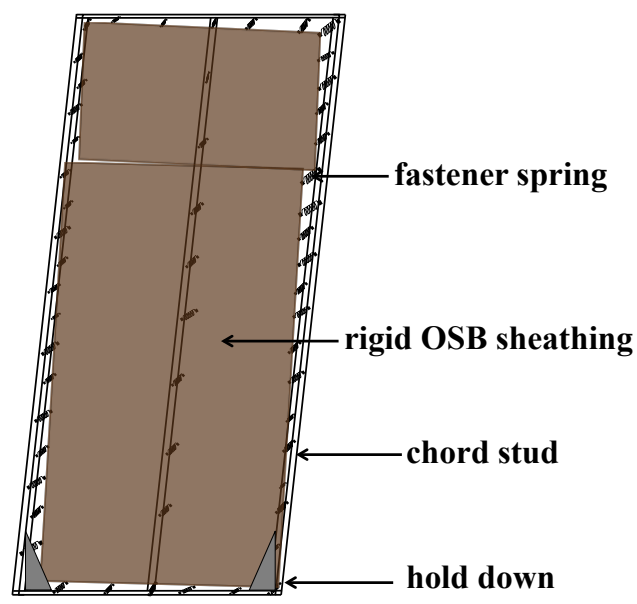

(c) deformed shape

Figure 2 Typical cold-formed steel framed shear wall in a ledger-framed building

As the wall is sheared an incompatibility exists between the CFS framing, which is

46 largely deforming as a parallelogram, and the wood sheathing that remains nearly

47 rectangular and primarily undergoes rigid body translation and rotation because of its 
large in-plane rigidity. The incompatibility between the deformed frame and sheathing causes a relative displacement that must be accommodated at the fasteners. This displacement causes tilting and bending of the fastener, as well as deformation and damage to the steel and wood sheathing material around the fastener. This damage is the source of yielding and energy dissipation in these systems [1,2] . The resulting overall CFS-framed wood-sheathed shear wall cyclic response exhibits significant hysteresis, degradation, and pinching, as shown in Figure 3.

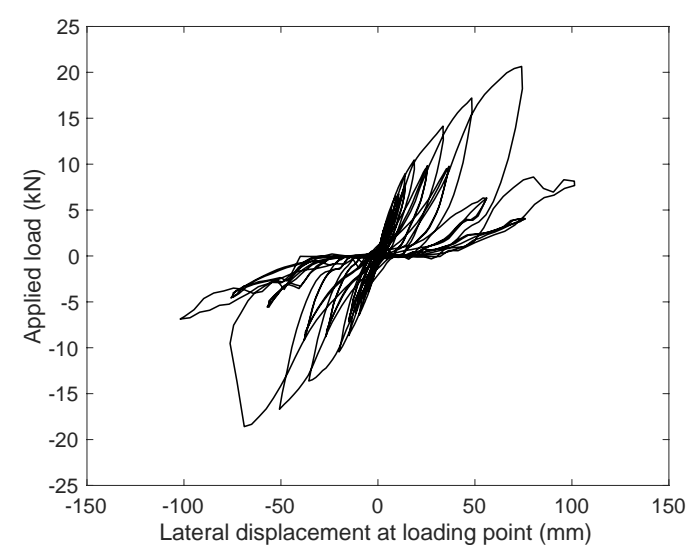

a. typical experimental response (adapted from [1])

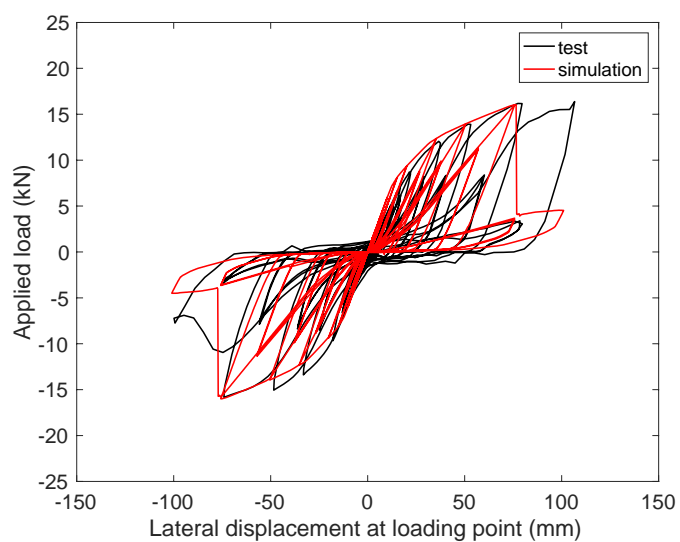

b. comparison between experiment and determinate simulation (adapted from [2])

Figure 3. CFS-framed wood sheathed shear wall cyclic response

CFS-framed wood-sheathed shear walls have been tested extensively. In North America AISI S400-15 [3] (previously AISI S213-07 and -12 [4] ) provides nominal shear wall strength for different types of sheathing, fastener spacing, and stud and track thickness based on the available testing (e.g., see [5,6] ). The shear wall strengths in AISI S400 are based directly on tested capacities, and a $\phi=0.6$ is used for the resistance factor in design. This value was selected initially based on typical $\phi$ value for steel deck diaphragms (which is based on a connector failure limit state and a target reliability, $\beta$, of 3.5) and has remain unchanged as additional entries to the tables in the standard have been included.

CFS-framed shear walls may be viewed as a small structural system - and system reliability for steel structures in general [7] and CFS structures in particular [9] has been studied recently. Monte Carlo (MC) simulation of models of steel frames have been used to assess component vs. system reliabilities and explore system-level resistance $(\phi)$ factors based on target system reliabilities as opposed to component reliability [8] . It has been shown that the system reliability of typical CFS framing under gravity demands far exceeds the individual component reliabilities [9]. Also, the reserve strength of CFS CFSframed floor diaphragms when considered as a system has been calculated [10]. .

Recognizing the central role that the nonlinear response of the steel-fastener-sheathing connection has on the overall shear wall response Buonopane et al. developed and validated an OpenSees simulation that adequately predicts CFS-framed wood-sheathed shear wall cyclic response [11]. This model provides the potential to conduct MC 
simulation of CFS-framed shear walls and explore the variability and reliability of their

80 response. This has the potential to provide improvements to the current reliability

81 assessment in AISI S400 [3] , which is essentially based on engineering judgment alone.

The work herein employs the validated shear wall model of Buonopane et al. [11] ,the shear wall tests of Liu et al. [1], and steel-fastener-sheathing connection tests of Peterman

85 et al. [12] to perform MC simulations on a series of CFS-framed shear walls and assess

86 the predicted reliability of the studied shear walls. The fastener testing is characterized in terms of a random variable and used to drive MC simulation of the selected shear walls. The simulation results are summarized and explored to provide insight on the importance of load redistribution, fastener location, and the resulting variability of shear wall strength. Next, the reliability of the peak strength based on the MC simulations is determined. Finally four potential shear wall design methods are considered and the reliability of these methods assessed against the available data both with and without

93 consideration of the system effect as discerned from the MC simulation. The paper

94 concludes with discussion of needed future work and the potential for further 95 incorporating system reliability into CFS-framing design.

\section{Selected CFS-framed OSB-sheathed shear walls}

As part of an overall research effort to improve CFS-framed seismic design, known as the CFS-NEES effort (see [13] ) Liu et al. conducted a series of monotonic and cyclic CFSframed, OSB-sheathed shear wall experiments [1]. The effect of construction details on shear wall behavior, including dimension, thickness of studs, and seam location, etc., were explored in the experiments. Typical shear wall configurations for $1.22 \mathrm{~m}$ and 2.44 $\mathrm{m}$ wide walls are provided in Figure 4 and complete details are provided in [1]. These experiments are independent from the testing used to formulate AISI S400 and since they were conducted under the purview of this same research team all details were available for the simulations performed herein. 

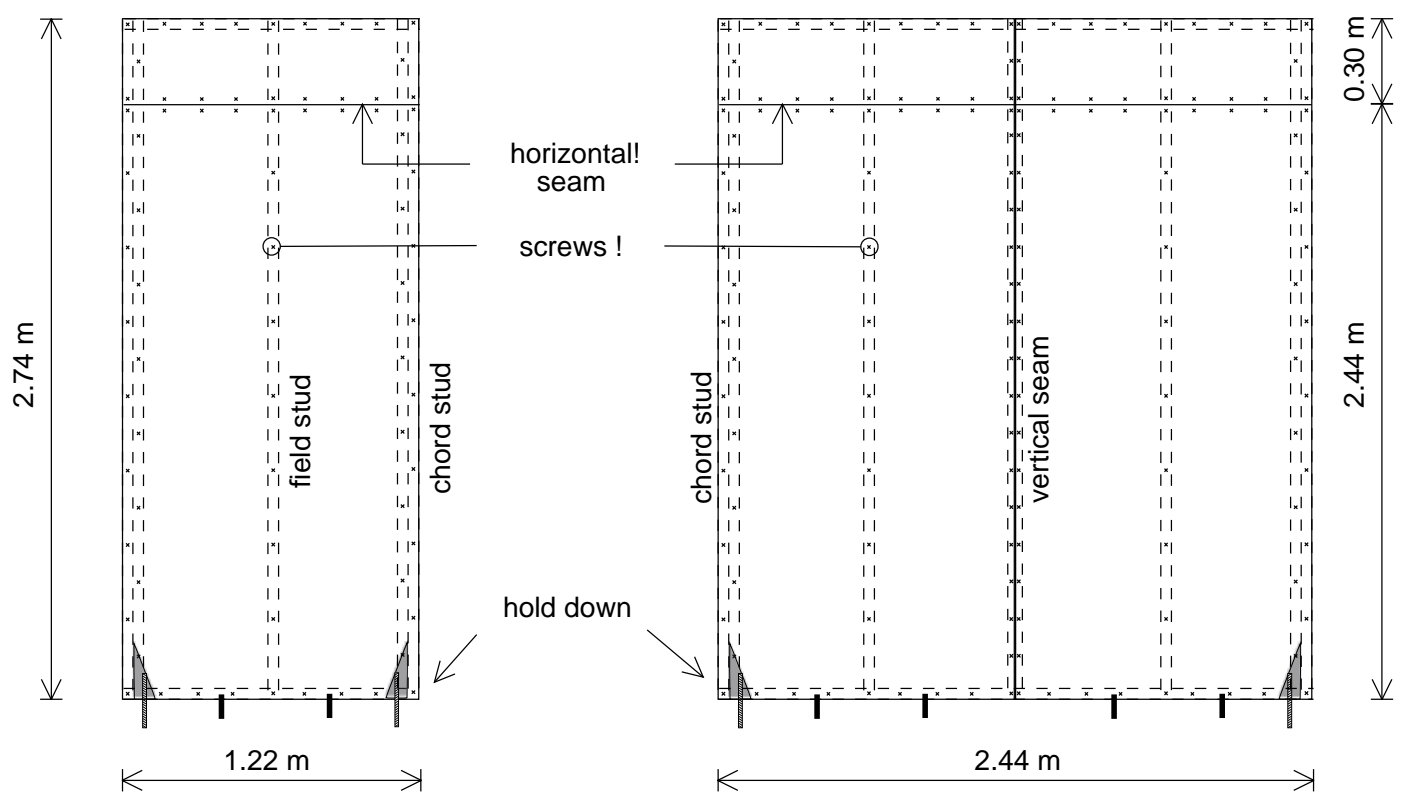

108

109

110

111

112

113

114

Figure 4. Two shear wall configurations of Liu et al. CFS shear wall tests: $1.22 \mathrm{~m}$ width and $2.44 \mathrm{~m}$ width

Twelve shear wall configurations, as summarized in Table 1, from Liu's test series were selected to conduct reliability evaluation of CFS-framed shear walls. These same walls were considered deterministically in Buonopane et al. [11] where a model for predicting the strength based on local nonlinear fastener response was developed.

Table 1 Selected shear walls from Liu et al. [1] test

\begin{tabular}{|c|c|c|c|c|c|c|c|}
\hline $\begin{array}{c}\text { Test or } \\
\text { Model } \\
\text { Number } \\
\end{array}$ & $\begin{array}{l}\text { Size } \\
(\mathrm{mxm})\end{array}$ & $\begin{array}{c}\text { OSB } \\
\text { sheathing }\end{array}$ & $\begin{array}{l}\text { Gypsum } \\
\text { sheathing }\end{array}$ & Ledger & $\begin{array}{c}\text { Horizontal } \\
\text { seam } \\
(\mathrm{mm}) \\
\end{array}$ & $\begin{array}{l}\text { Vertical } \\
\text { seam } \\
(\mathrm{mm}) \\
\end{array}$ & $\begin{array}{c}\text { Tested } \\
\text { strength } \\
(\mathrm{kN})\end{array}$ \\
\hline 1 & $1.22 \times 2.74$ & $\bar{\square}$ & - & $\bar{\square}$ & 2438 up & - & 21.82 \\
\hline 2 & $1.22 \times 2.74$ & Q & Q & Q & 2438 up & - & 22.43 \\
\hline 3 & $1.22 \times 2.74$ & Q & - & - & 2438 up & - & 18.65 \\
\hline 4 & $1.22 \times 2.74$ & Q & - & Q & 2133 up & - & 18.17 \\
\hline 5 & $1.22 \times 2.74$ & ૫ & - & - & 2133 up & - & 21.95 \\
\hline 6 & $1.22 \times 2.74$ & Q & - & - & 2133 up & 305 over & 15.61 \\
\hline $7 *$ & $1.22 \times 2.74$ & प & - & - & 2438 up & 610 over & 18.41 \\
\hline 8 & $1.22 \times 2.74$ & Q & - & - & 2438 up & 610 over & 16.34 \\
\hline 9 & $1.22 \times 2.74$ & Q & - & - & 1372 up & 610 over & 16.95 \\
\hline 10 & $2.44 \times 2.74$ & Q & - & Q & 2438 up & - & 38.77 \\
\hline 11 & $2.44 \times 2.74$ & Q & Q & ૫ & 2438 up & - & 47.30 \\
\hline 12 & $2.44 \times 2.74$ & ૫ & - & - & 2438 up & - & 37.55 \\
\hline
\end{tabular}

*Note: in test 7 , there is additional one field stud $0.3 \mathrm{~m}$ over from side. Details see Liu et al.[1]

\section{Fastener-based modeling of CFS-framed shear walls}

Buonopane et al. [11] developed and validated a structural model for CFS-framed woodsheathed shear walls in OpenSees[14]. The model consists of elastic beam-column elements for all steel framing, rigid diaphragm elements for each individual sheathing 
board, linear springs for steel-to-steel connections such as the stud to track, and nonlinear springs for all steel-fastener-sheathing connections (Table 2 summarizes and [11] provides all further details). The model was able to reproduce key characteristics of the force-displacement hysteretic response of shear wall tests without calibration. The model reasonably predicted peak strength, and displacement at peak strength, as well as per cycle and total energy dissipation. The model does not capture failure modes outside of the fasteners - i.e. in the chord studs, track, or hold-down, and ignores torsion effects from one-sided sheathing applications. The provided model is only valid insofar as failure is precipitated at the fasteners.

In this model essentially all nonlinearity in response is derived from the connection model and is thus referred to as a fastener-based model for a shear wall. The model has a direct legacy in work on wood-framed shear walls (e.g., see [11] ) and has been used to characterize the response of CFS-framed shear walls for larger whole building models $[15,16]$. The model may include or exclude the performance of shear wall hold-downs depending on the measurements being compared against and the objective of the model. If included the nonlinearity of the hold-downs and the potential for bearing-based load transfer of the field and chord studs has been shown to be important $[15,16]$.

Table 2. Summary of materials and elements used in OpenSees models

\begin{tabular}{|c|c|c|c|c|}
\hline Component & $\begin{array}{l}\text { Engineering } \\
\text { designation }\end{array}$ & $\begin{array}{l}\text { Element } \\
\text { type }\end{array}$ & $\begin{array}{l}\text { Element in } \\
\text { OpenSees }\end{array}$ & $\begin{array}{l}\text { Material in } \\
\text { OpenSees }\end{array}$ \\
\hline stud & $600 \mathrm{~S} 162-54$ & $\begin{array}{c}\text { Euler-Bernoulli } \\
\text { beam }\end{array}$ & DispBeamColumn & linear elastic \\
\hline track & $600 \mathrm{~T} 150-54$ & $\begin{array}{c}\text { Euler-Bernoulli } \\
\text { beam }\end{array}$ & DispBeamColumn & linear elastic \\
\hline strap & $11 / 2 \mathrm{in} . \times 54 \mathrm{mil}$ & $\begin{array}{c}\text { Euler-Bernoulli } \\
\text { beam }\end{array}$ & DispBeamColumn & linear elastic \\
\hline ledger track & 1200T200-97 & $\begin{array}{c}\text { Euler-Bernoulli } \\
\text { beam }\end{array}$ & DispBeamColumn & linear elastic \\
\hline sheathing & $\begin{array}{c}\text { Oriented Strand } \\
\text { Board }\end{array}$ & $\begin{array}{l}\text { Multi-Point } \\
\text { constraint }\end{array}$ & RigidDiaphragm & - \\
\hline $\begin{array}{l}\text { sheathing fastener } \\
\text { (wood-to-steel) }\end{array}$ & $\begin{array}{c}\text { \#8 or \#10 flathead } \\
\text { screw }\end{array}$ & Spring element & CoupledZeroLength & Pinching04 \\
\hline hold-down & Simpson S/HDU6 & Spring element & $\begin{array}{l}\text { Zero-length } \\
\text { element }\end{array}$ & linear elastic \\
\hline $\begin{array}{l}\text { steel fastener } \\
\text { (stud-to-track) }\end{array}$ & \#10 flathead screw & Spring element & Rotational spring & $\begin{array}{l}\text { Rotational } \\
\text { stiffness at } 11.3 \\
\mathrm{kN}-\mathrm{m} / \mathrm{rad}\end{array}$ \\
\hline
\end{tabular}

142

The steel studs are modeled with displacement-based beam column elements and actual cross section properties are assigned to the element. The studs are connected to the top and bottom tracks with rotational spring elements. The rotational stiffness for the spring element was estimated to be $11.3 \mathrm{kN}-\mathrm{m} / \mathrm{rad}$ based on the bare CFS frames test [1] . The hold-downs are modeled as uniaxial spring elements in the vertical direction. A tension stiffness of $9.9 \mathrm{kN} / \mathrm{mm}$ [8] was assigned to the hold-down elements, and a compression stiffness 1000 times as large as tension to simulate a rigid foundation. The KrylovNewton algorithm is used as the solver in OpenSees. 
The steel-fastener-sheathing connection is modeled using the Pinching04 material [17] in 153 OpenSees and zero-length radial springs in the fastener-based model. Pinching04 is a one 154 dimensional hysteretic material model which employs 4 linear segments for its

\section{Characterization of fastener properties as random variables}

The nonlinear shear response of a fastener connected through sheathing to steel can be determined in isolated testing. Motivated from work in sheathing braced design of studs [18] a small test rig was modified by Peterman et al. [12] and used to generate monotonic and cyclic response of steel-fastener-sheathing combinations consistent with the shear wall testing in [1] .The testing rig consists of installing two standard studs in a universal uniaxial testing machine, attaching the studs with sheathing, and finally cycling the resulting specimen. For symmetry two fasteners are placed between the sheathing and the stud and both faces of the stud are sheathed. Focusing on a single fastener, before and after testing, the results for a typical test are provided in Figure 5.

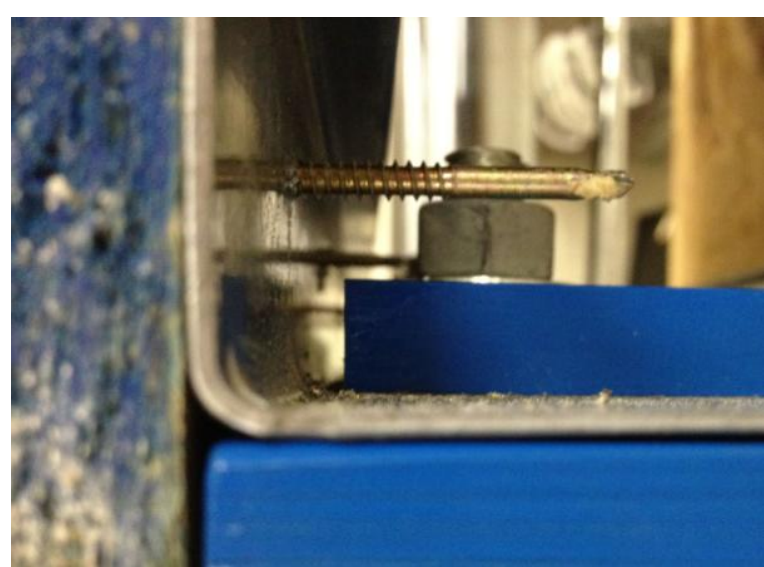

(a) prior to testing

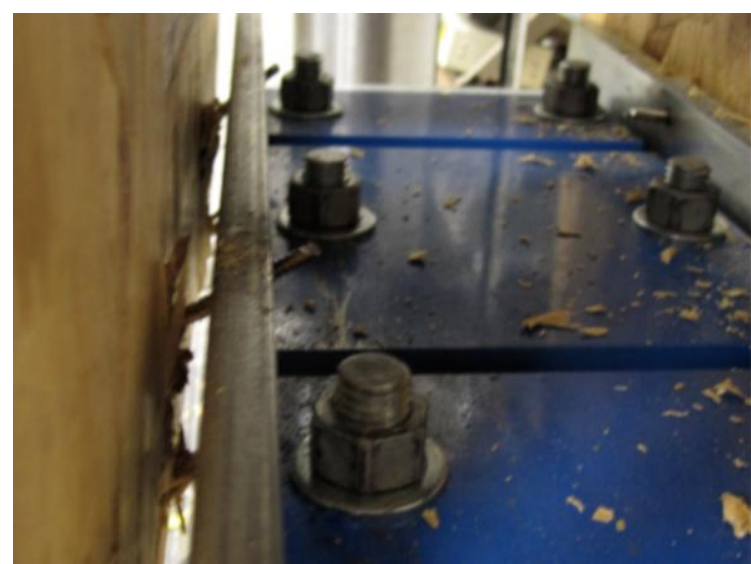

(b) after failure

\subsection{Fastener test data and its backbone curve assumption}

Considering the subset of testing relevant for the analyses performed herein, the monotonic tests on \#8 fasteners drilled through $11.1 \mathrm{~mm}$ [7/16 in.] OSB sheathing and anchored in $1.4 \mathrm{~mm}$ [54 mil = $0.054 \mathrm{in}$.] steel are provided in Figure 6a. Results are included for both tested fastener spacings: $152.4 \mathrm{~mm}$ (6 in.) and $304.8 \mathrm{~mm}$ (12 in.), since Peterman et al. showed that fastener spacing did not influence the local shear 
response[12] .The Pinching04 material model provides 4 linear segments that may be employed in approximating the backbone response. Consistent with past work, the backbone was constructed by utilizing the response at $40 \%$ peak load, $80 \%$ peak load, peak load, and mean load at largest tested displacement as illustrated in Figure 6b. The post-peak model was considered in one of two ways: (a) brittle - following the average post-peak response or (b) idealized-ductile - following the ideal ductile post-peak response. These two variants are used later in the simulations to understand the impact of the post-peak fastener behavior on the variability of the shear wall response.

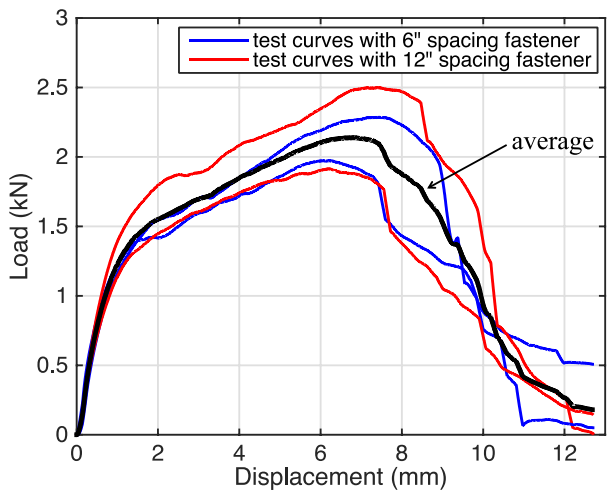

(a) example of fastener test curves

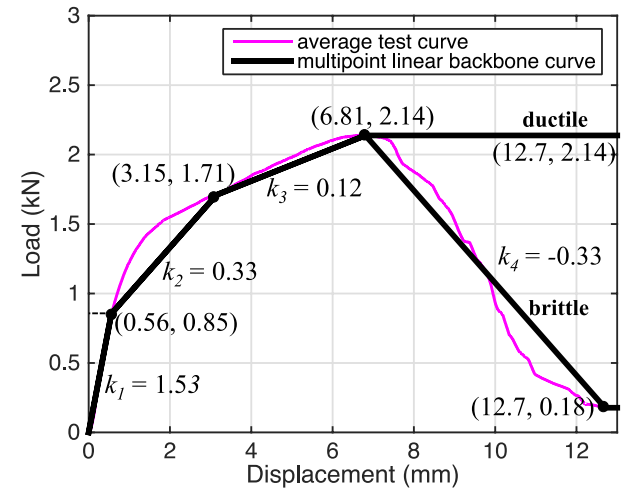

(c) selected average fit from test data for $11.1 \mathrm{~mm}$ OSB sheathing and \#8 screws to 54 mil steel

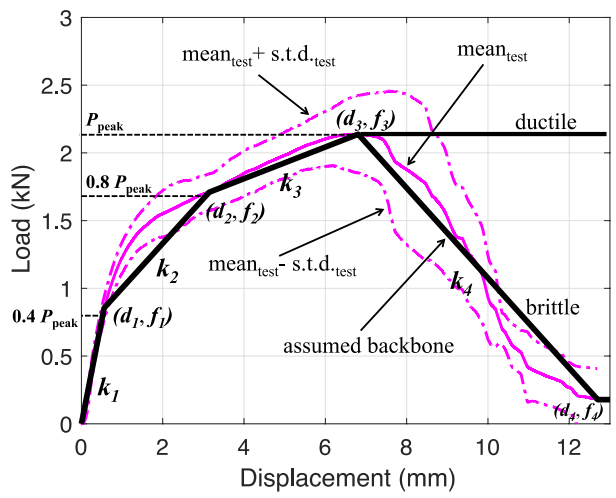

(b) conceptual Pinching04 fit to test data

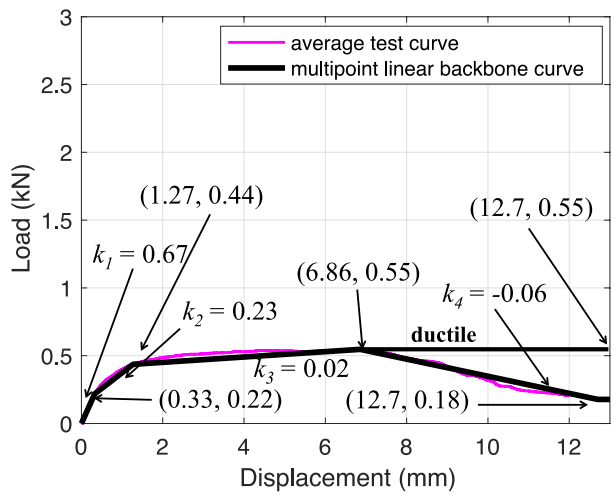

(d) selected average fit from test data for Gypsum board and \#6 screws to 54 mil steel

Figure 6. Sheathing-fastener-steel connection shear backbone response models

\subsection{Generation of random fastener backbones}

For development of simulations fastener peak strength $f_{3}$ was chosen as the only independent random variable. All other backbone parameters are generated as dependent on peak strength, i.e. are perfectly correlated with $f_{3}$. From the test data for a \#8 fastener in $11.1 \mathrm{~mm}$ OSB sheathing and $1.4 \mathrm{~mm}$ steel the mean $\left(\mu_{f 3}\right)$ and standard deviation $\left(\sigma_{f 3}\right)$ of the fastener strength is $2.14 \mathrm{kN}$ and $0.28 \mathrm{kN}$ respectively. Therefore, the coefficient of variation (C.O.V.) of the peak fastener strength $\left(V_{f 3}\right)=0.28 / 2.14=13 \%$. 
The authors have conducted a large number of fastener tests with similar (fasteners through sheathing anchored in steel sheet and exercised in shear) but not identical details (steel thickness, fastener type, sheathing thickness) to those used here [10]. These fastener peak strengths were log-transformed and then a Lilliefors test was applied to the transformed data. The resulting P-value is 0.4278 , which is well above the typical threshold e.g. 0.05 for normality. Therefore, we assumed $f_{3}$ as lognormal and defined $40 \% f_{3}$ and $80 \% f_{3}$ as equal to $f_{1}$ and $f_{2}$ respectively. For the brittle fastener backbone $f_{4}$ is set to $0.18 \mathrm{kN}$ and in the ductile model $f_{4}$ equals $f_{3}$. (The final plateau strength established by $f_{4}$ generally is used to improve numerical stability of the models. In the subsequent simulations for shear walls none of the fastener model response is in this final plateau regime at peak shear wall strength, although it is common to be in the descending branch). All secant stiffness for different branches in the random fastener backbone are the same as in the deterministic multipoint linear backbone curve. With these assumptions we can define displacement as $d_{1}=f_{1} / k_{1}, d_{2}=d_{1}+\left(f_{2}-f_{1}\right) / k_{2}, d_{3}=d_{2}+\left(f_{3}-f_{2}\right) / k_{3}$, and $d_{4}=d_{3}+\left(d_{4}-d_{3}\right) / k_{4}$ for the brittle fastener and $d_{4}=20 \mathrm{~mm}$ for the ductile fastener case. After $20 \mathrm{~mm}$ for the ductile case, the ductile plateau goes to infinity.

The resulting process for generation of random backbones is illustrated in Figure 7. Peak strength is simulated as a lognormal random variable and both brittle and idealized ductile fastener backbone curves can be automatically generated. The process is relatively straightforward - having only a single random variable and resulting in realizations that never cross in force-displacement space. However, it does capture the behavior observed in testing and provides a wide scatter of potential fastener response. The generated brittle and ductile fastener backbones are used in next section for MC simulations of the shear wall response. Different random backbones were generated for different fasteners in the shear walls and assumed fasteners were uncorrelated in the shear walls.

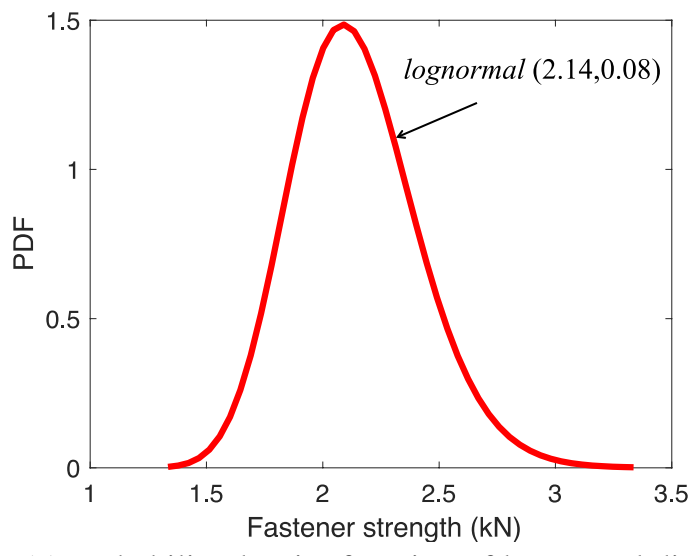

(a) probability density function of lognormal dist.

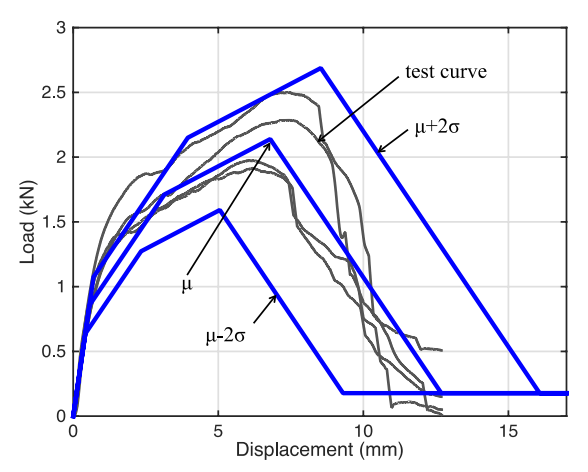

(b) fastener strength and fastener test curve 


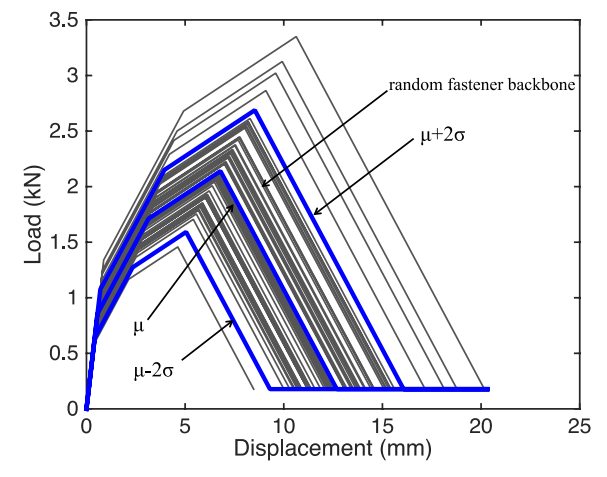

(c) brittle random fastener backbone model

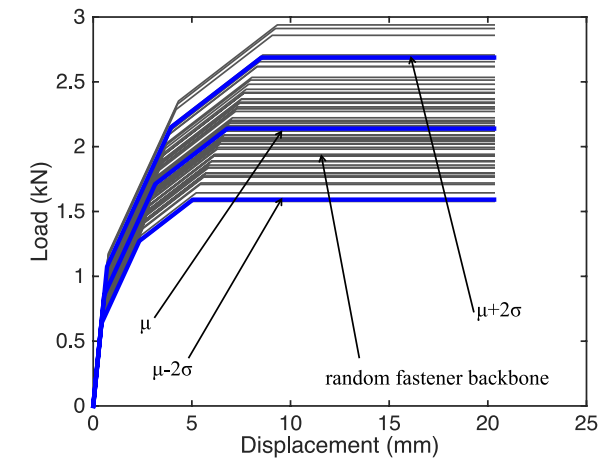

(d) ductile random fastener backbone model

Figure 7. Distribution and random fastener backbones for brittle and ductile model

\section{Monte Carlo simulation of shear wall pushover response}

MC simulation is a brute force technique for studying the stochastic response of a system. A series of deterministic models are generated based on assumptions about the randomness in the system. For a large enough number of samples the assumption is that the statistics of the response of the system converge towards the actual probabilistic response. For the simulations performed here the first two moments of the peak strength of the shear wall (i.e. mean and variance of the shear wall strength) are of particular interest and convergence occurs within 1000 simulations.

\subsection{Monte Carlo Simulation of shear wall with brittle fastener model}

A typical shear wall test specimen (test 1c in[1] ) was selected to conduct MC Simulation. The dimension and configuration details are provided in Table 1. For this study 1000 pushover simulations were conducted with the fastener-based shear wall model, each with 70 independent identical distributed (iid) random (brittle) fastener backbone models. Effectively one draw in the MC simulation of the wall includes the 70 iid fasteners, and then a pushover analysis is conducted and the response recorded. The second draw includes a new 70 iid fasteners, and this continues for 1000 total draws draws such that statistics of the pushover simulation itself can be estimated.

The lateral load displacement curves and histogram of peak strength are shown in Figure 8 (a) and (b), respectively. Note, the underlying assumption of the fastener-based models, that the initial stiffness is constant, results in all 1000 simulations beginning with the same deterministic stiffness. To provide a comparison three additional deterministic models were run: (a) all fasteners were given the mean ( $\mu$ ) backbone response, (b) all fasteners were given the $\mu+1$ standard deviation $(\sigma)$ backbone response, and (c) all fasteners were given the $\mu-\sigma$ fastener backbone response. Interestingly, the response of the shear wall is well within these bounds. In fact, even though the CoV of the fastener 
strength is $13 \%$ the $\mathrm{CoV}$ of the shear wall peak strength is less than $3 \%$. This reduction in variability is beneficial and suggests useful redistribution of load across fasteners within the shear wall under load; however, it is worth noting that the mean shear wall strength is $16.9 \mathrm{kN}$ compared with $17.2 \mathrm{kN}$ for the deterministic model based on average properties, indicating not all system effects are beneficial. Thus, a design that uses mean fastener properties to predict the mean strength of the shear wall will modestly over-estimate the mean shear wall strength.

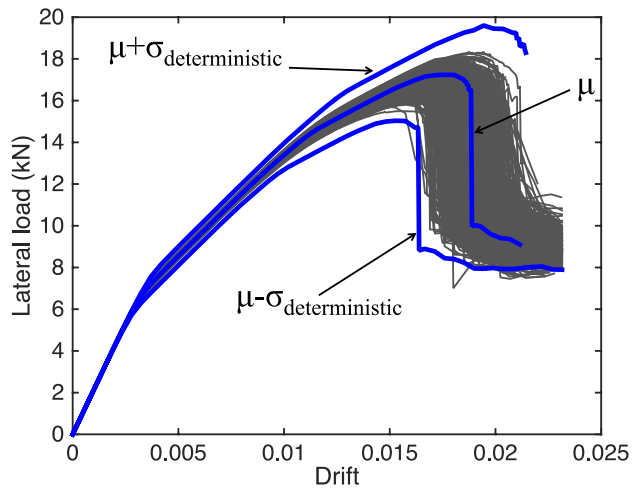

(a)

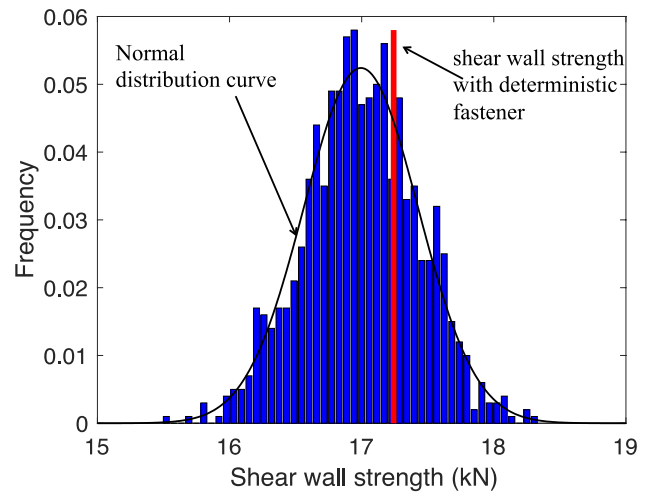

(b)

Figure 8. Shear wall load-drift curve with 1000 realizations and its histogram with brittle fastener model

The utilization of the fasteners within the shear wall may be measured by their demandto-capacity (DC) ratio. For each fastener in the shear wall, we defined the DC ratio as the ratio of the fastener force at shear wall peak strength to the fastener capacity of the individually sampled fastener strength (i.e. each individual realization of $f_{3}$ ). The average DC ratio for each fastener based on $1000 \mathrm{MC}$ simulations at $1.5 \%$ wall drift and at shear wall peak strength are provided in Figure 9 (a) and (b), respectively. 


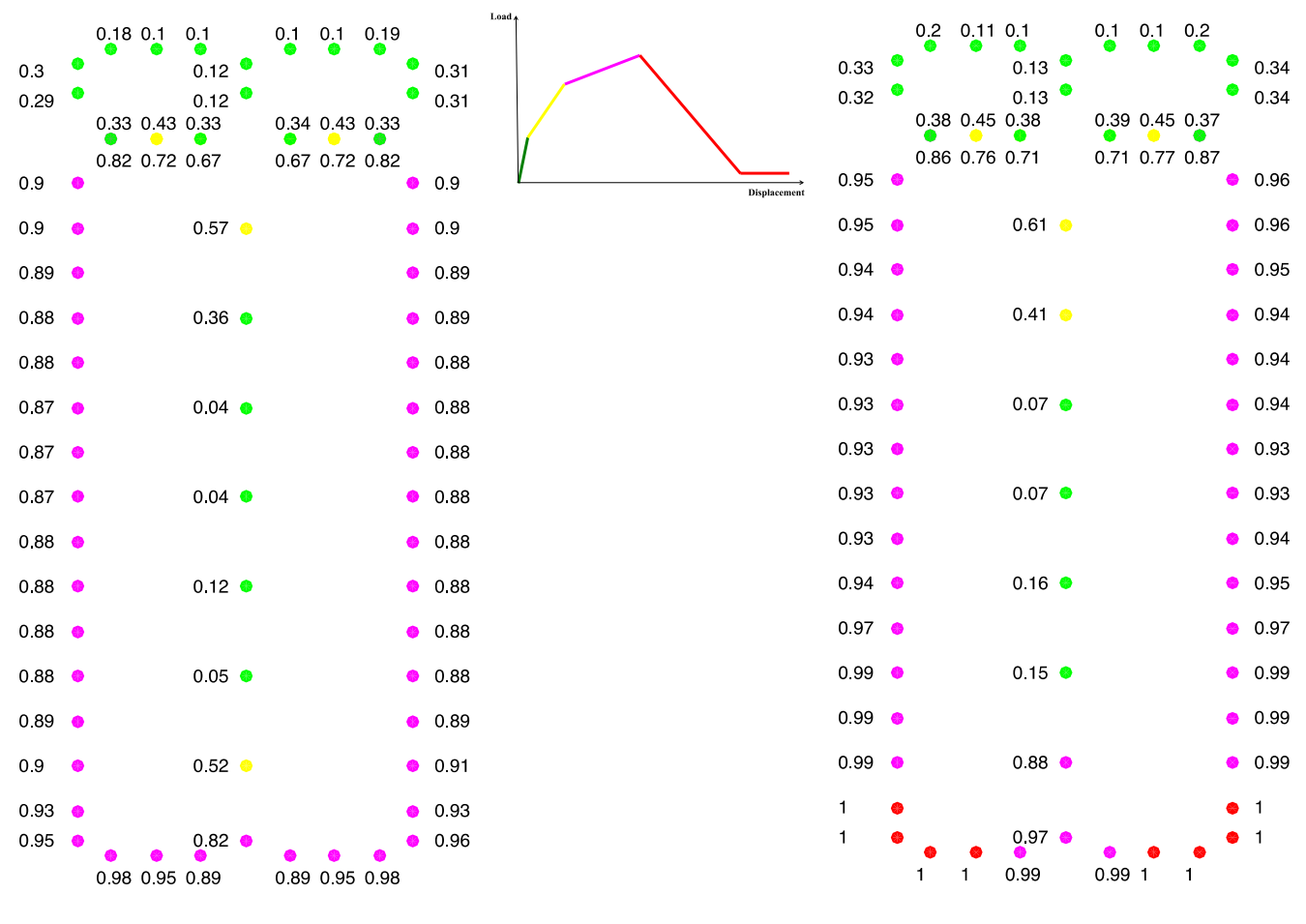

(a) at $1.5 \%$ shear wall drift

(b) at shear wall peak strength

Figure 9. Average shear wall fastener demand-to-capacity ratios

279 Fasteners in the bottom corners have the highest DC ratios, at or approaching 1.0 even bottom are in the post-peak response range. Fasteners in the upper portion of the shear wall are not highly utilized because the ledger framing at the top of the shear wall provides substantial frame bending resistance in addition to the fastener-based resistance.

In shear walls, fasteners work as groups. Fastener failure, or degradation in fastener stiffness, is mitigated by closely spaced neighboring fasteners that can carry additional force. To explore these fastener group effects we divided the fasteners into groups, and compared the correlation coefficient for the weakest fastener strength and shear wall strength. Fasteners at the same location, and with similar DC ratios were divided into the same fastener group. Figure 10 (a) - (f) illustrate the correlation coefficient for the six selected fastener groups. In the bottom corner of the shear wall the correlation coefficient is 0.45 while it is only 0.003 for the fastener group at the horizontal seam location. The failure of a single fastener does not equate to failure of the shear wall, but the failure of fastener in the bottom is more important than in other locations. Figure 10 provides a means to understand the relative importance of fastener location in a typical shear wall. 

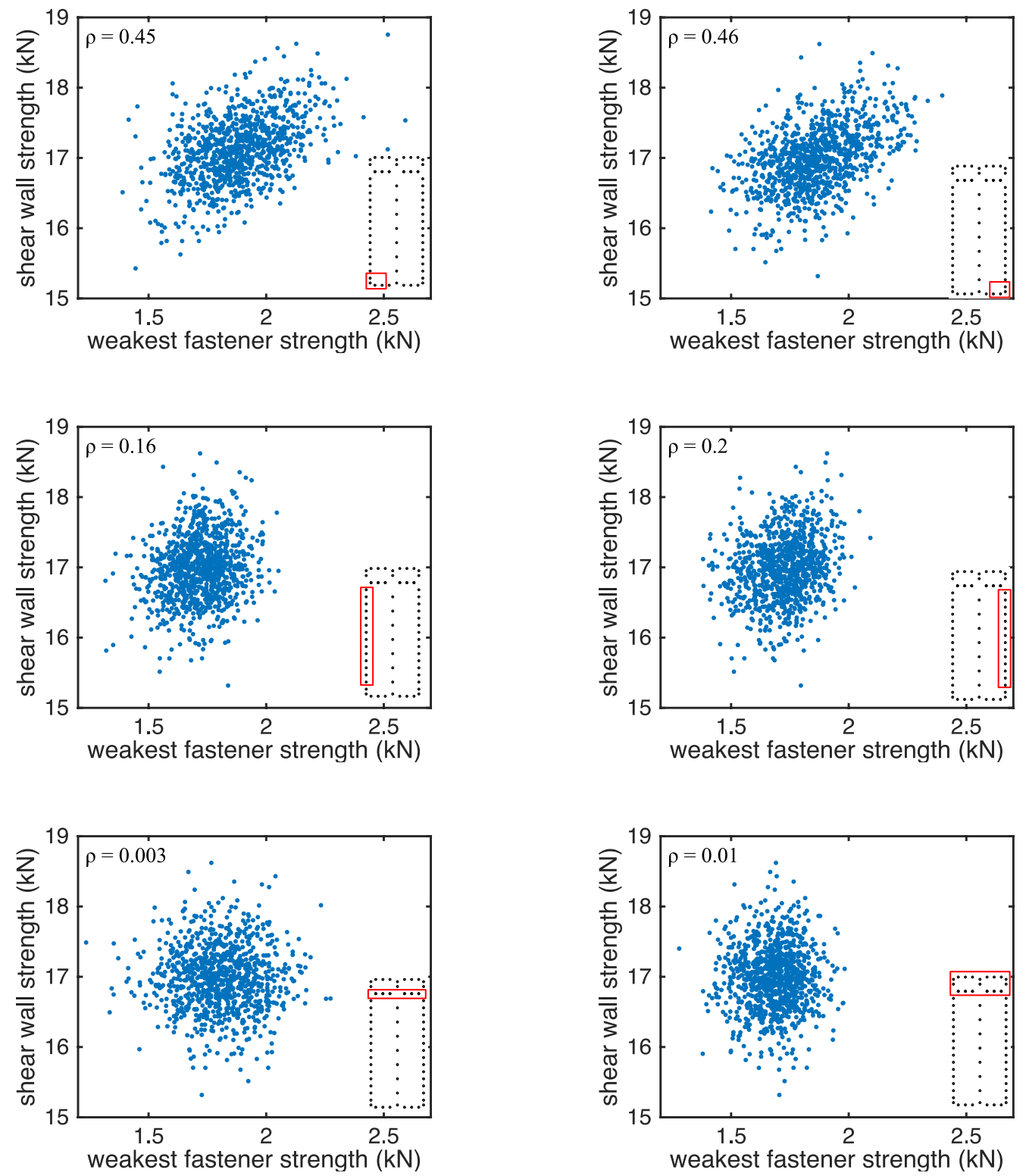

Figure 10. Correlation coefficient between shear wall strength and fastener groups at peak strength for brittle shear wall models

\subsection{Monte Carlo Simulation of shear wall with ductile fastener model}

Ideally, fasteners would have fully ductile response and thus allow for weaker fasteners to always redistribute to stronger fasteners. To understand the impact of this ideal case MC simulation employing the idealized ductile fastener model was also conducted. 1000 simulations were conducted for shear wall 1 and the results are summarized here. Unlike the brittle fastener simulations, peak load is only reached when every fastener has yielded and this leads to unrealistic wall drifts, therefore a maximum $101.6 \mathrm{~mm}$ [4 in.] or $3.7 \%$ 
drift was allowed. This drift is consistent with maximum drift observed in related testing (see, e.g. [1]). Shear force-displacement response and a histogram of "peak" strength at $3.7 \%$ drift are provided in Figure 11. The deterministic models with fastener inputs at $\mu$ and $\mu+/-\sigma$ are also provided again for comparison. As before the shear wall peak strength variability $(\mathrm{CoV}$ of $3 \%)$ is far less than the input variability on the peak fastener strength ( $\mathrm{CoV}$ of $13 \%)$. However, this time, in the fully ductile model the average wall strength is equal to a deterministic model based on average fastener strength. As expected, no detrimental system effects are observed in the case of idealized, fully ductile, fastener response.

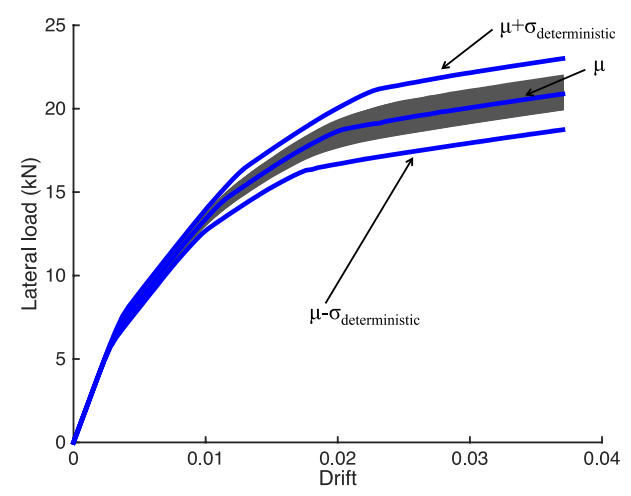

(a)

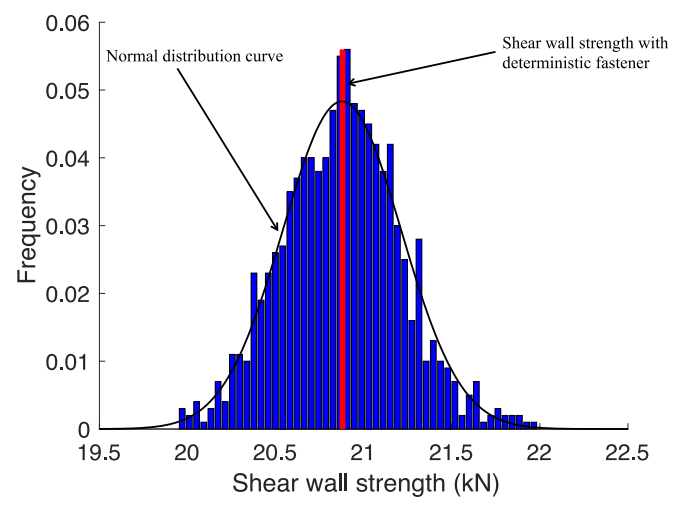

(b)
319

320

321

322

323

324

325

326

327

328

Figure 11. Shear wall load-drift curve with 1000 realizations and its histogram with ductile fastener model

Correlation between the weakest fastener in a selected group and the shear wall peak strength are provided for the ductile model in Figure 12. Compared with the brittle model results, the ductile model shows lower correlation for those fasteners that initially have high DC ratios. This is consistent with the complete redistribution that is allowed in the idealized ductile fastener case. Since the fastener has ductile behavior, even the weak fasteners can indefinitely carry force, and allow load redistribution. This redistribution results in fastener location having even less correlation to shear wall strength.
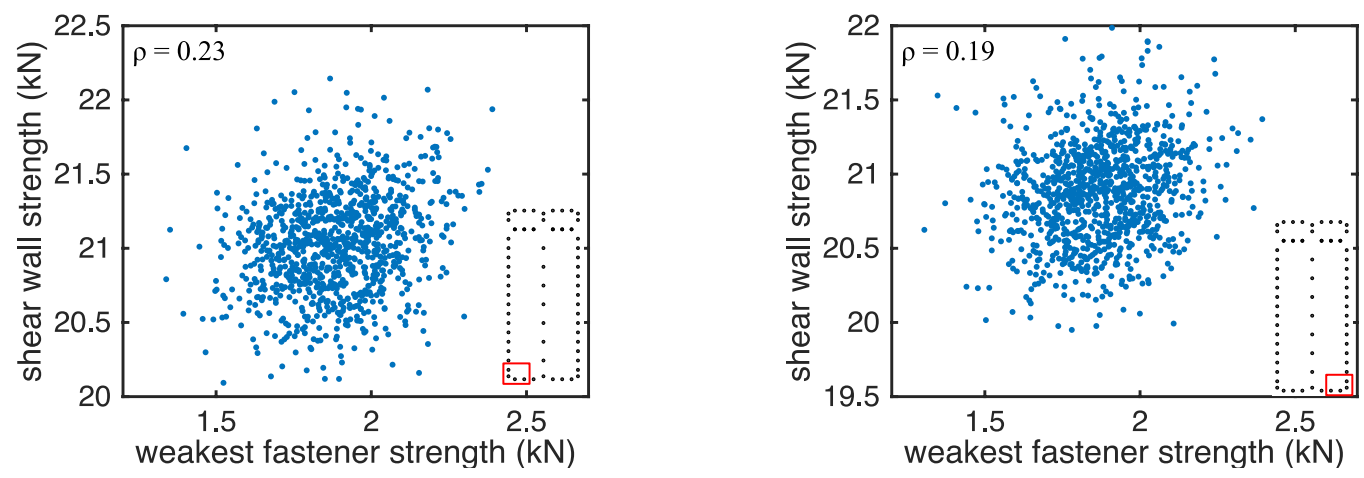

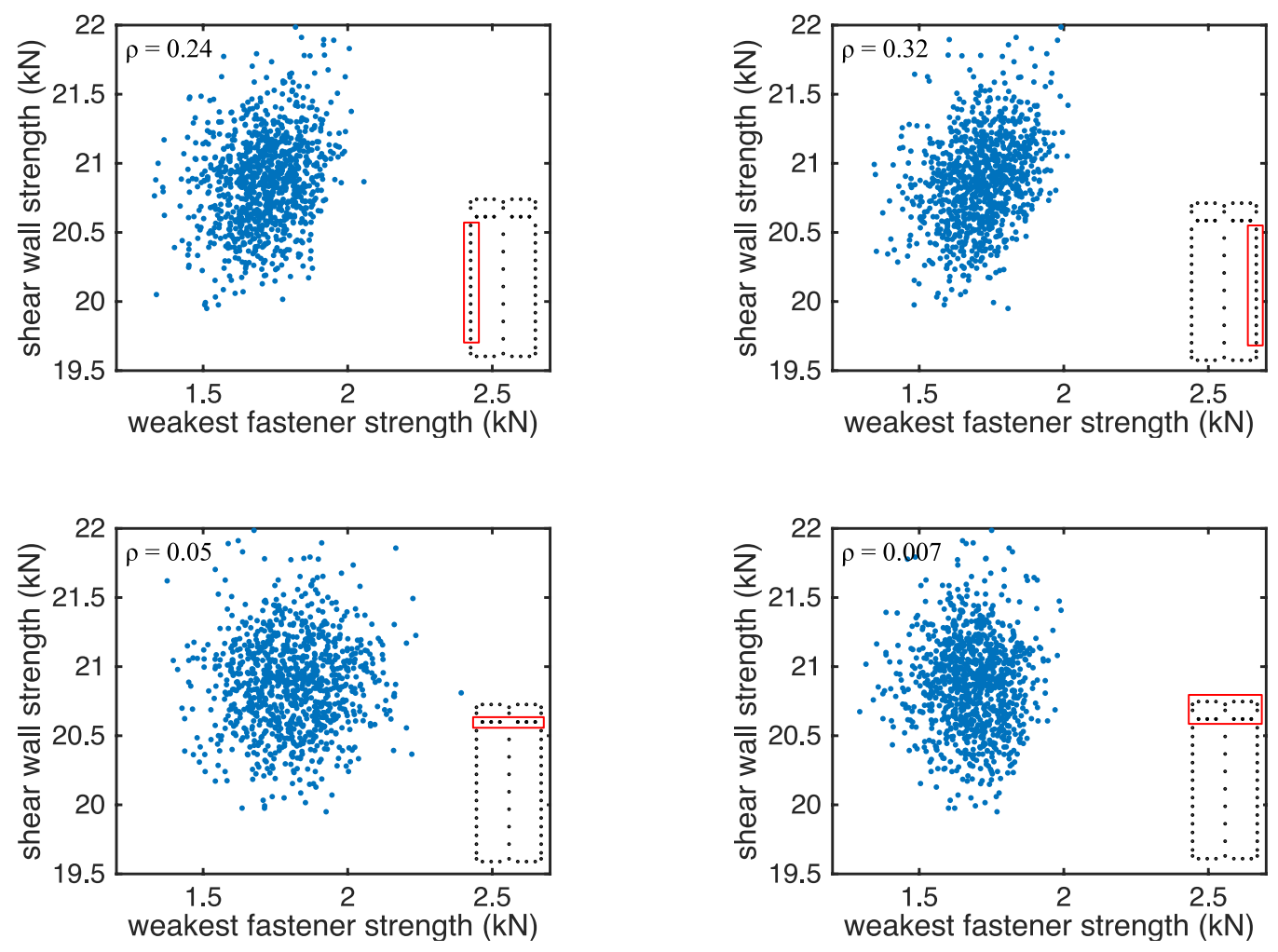

Figure 12. Correlation coefficient between shear wall strength and fastener groups at peak strength for ductile shear wall models

The simulations indicate that variability in response increases with drift (e.g. Figure 8a). To examine this we provided histograms of the shear wall strength at $0.5,1.0$, and $1.5 \%$ wall drift in Figure 13. The standard deviation in strength increases from less than $1 \%$ to almost $2 \%$ over the studied drift range and the brittle fastener model has slightly higher variability. However, the absolute magnitude of the variability is small (variance is 0.04 $\mathrm{kN}^{2}$ at the maximum). 

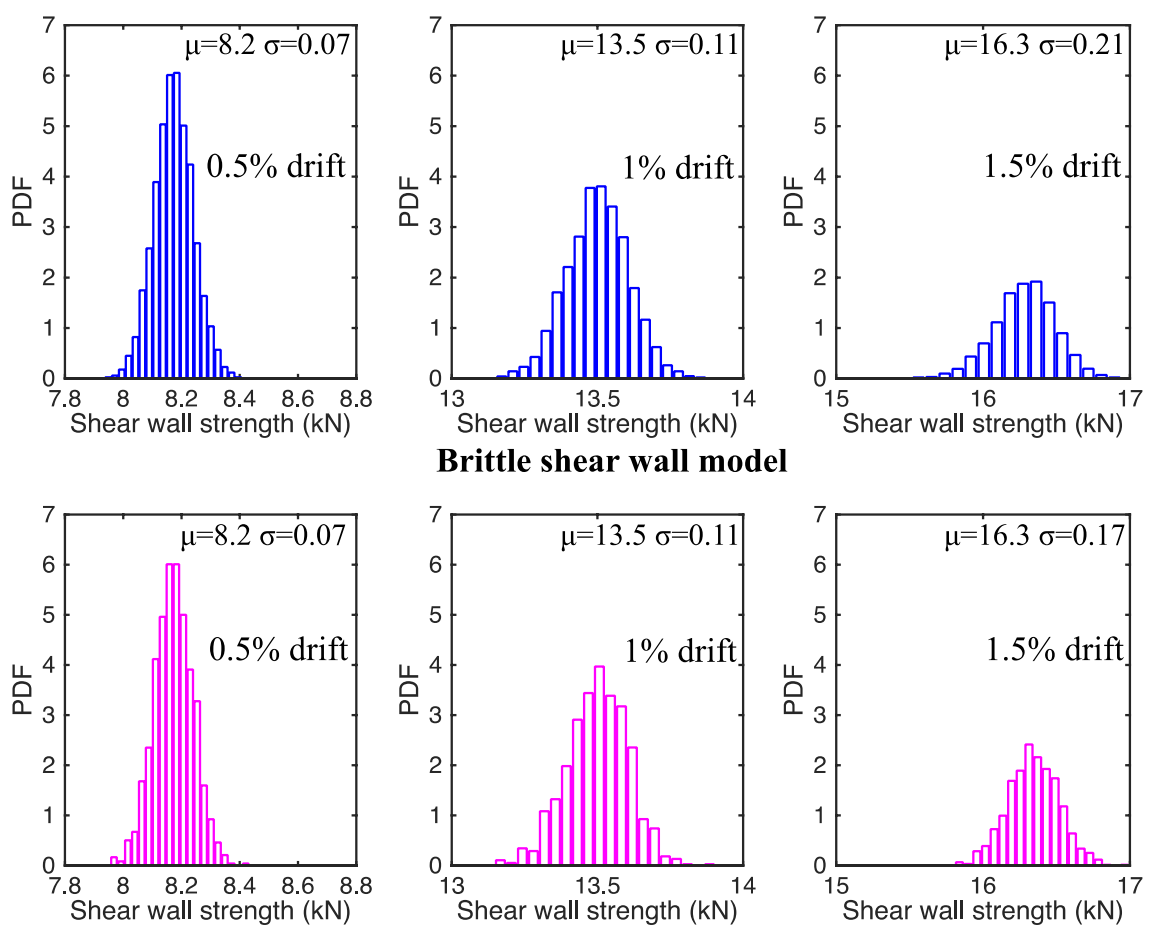

Ductile shear wall model

Figure 13. Shear wall strength histogram under different drift

\section{2}

343

344

345

346

347

348

349

350

351

352

353

354

355

356

357

358

359

360

361

362

363

\subsection{Statistical results for all studied shear wall configurations}

The testing detailed in Section 2 (Figure 4 and Table 1) covers a range of shear wall construction spanning the conditions employed in a prototype two-story cold-formed steel framed building (see Schafer et al. [13] ). In this section MC simulation was extended to all twelve shear wall configurations reported in Section 2. Shear wall model with brittle connections was used in all simulations.

For each shear wall configuration Monte Carlo simulations were performed. The mean $\left(\mu_{M C}\right)$, standard deviation $\left(\sigma_{M C}\right)$ and $\operatorname{CoV}\left(V_{M C}\right)$ for the peak strength from the simulations is reported in Table 3. In addition the mean peak strength from the MC simulation is compared to the peak strength based on a single deterministic pushover analysis using average fastener properties $\left(F_{D e t}\right)$ in Table 3 . Tested shear wall strength is also listed in the table and compared with $\mathrm{MC}$ mean strength. Across all configurations $\mu_{M C}<F_{D e t}$ indicating the mean system strength is slightly lower than the expected strength based on the mean component strength. This is indicative of a series system; however, the ratio is only slightly less than 1.0 (average is 0.97 ) so the system effect on the mean strength is only modestly negative. Shear wall strength from the simulations is generally similar to the tested strength - walls with more conservative simulation prediction generally have larger numbers of sheathing boards and seams and contact between the boards is not included in the developed model; see [11] for further discussion. 
The dispersion in results across the 12 studied tests is depicted in the box and whisker plots of Figure 14. Results are again normalized by $F_{\text {Det }}$. Mean values are slightly less than 1.0 and dispersion is consistently small. The average $\mathrm{CoV}$ in peak shear wall strength for the studied shear walls is $2.3 \%$ and the maximum $\mathrm{CoV}$ is $3.0 \%$ considerably less than that $\mathrm{CoV}$ of the peak fastener strength which is $13 \%$. With respect to variability, the system effect in a shear wall is highly beneficial.

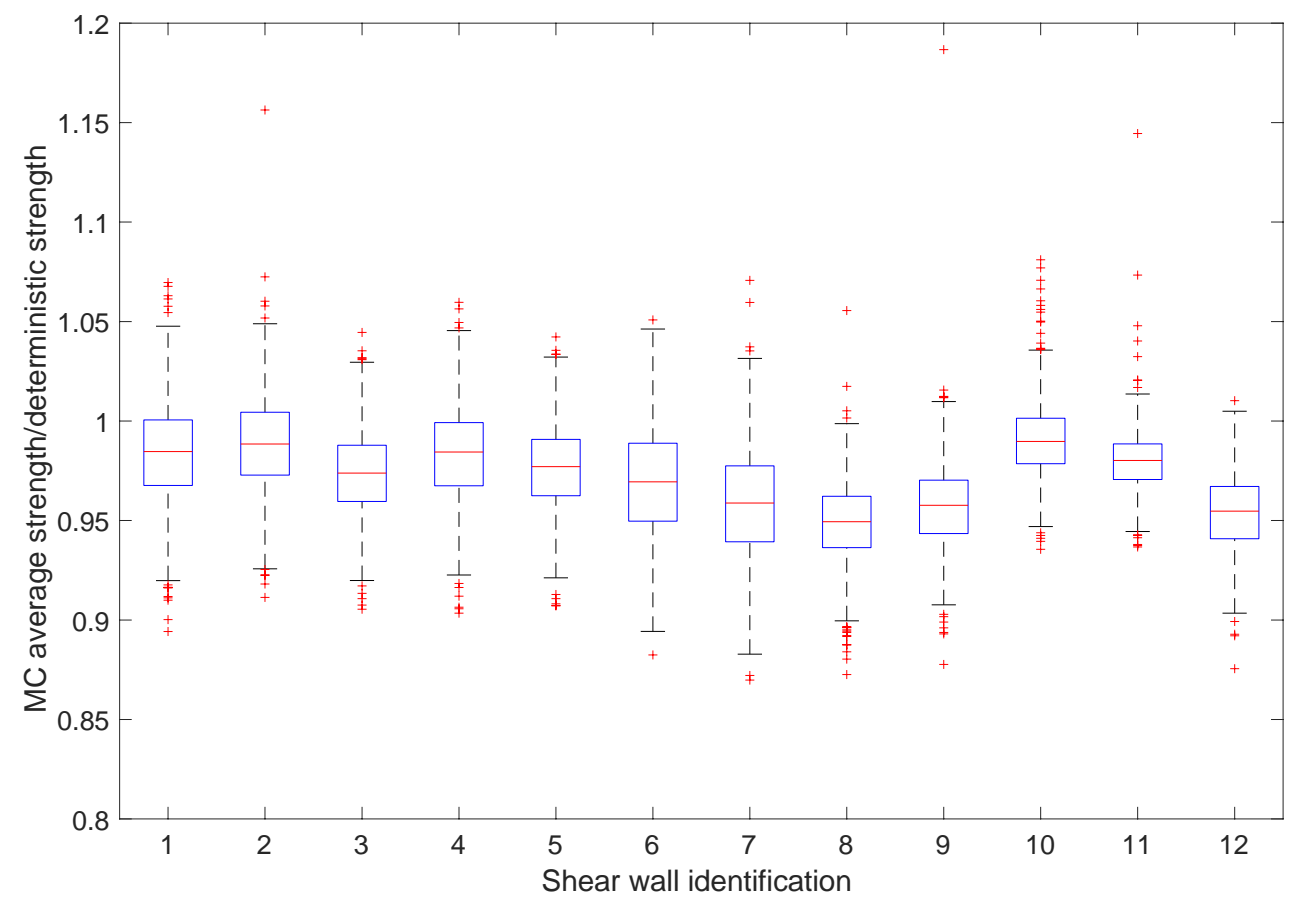

Figure 14. Box-and-whisker plot of shear wall Monte Carlo Simulation strength/deterministic shear wall strength ratio

Table 3 Predicted peak strength for all selected shear wall configurations

\begin{tabular}{cccccccc}
\hline \multicolumn{3}{c}{ MC Simulation } & \multicolumn{3}{c}{ Deterministic } & \multicolumn{3}{c}{ Experiment } \\
\hline $\begin{array}{c}\text { Model } \\
\text { No. }\end{array}$ & $\mu_{\square \square}$ & $\begin{array}{c}\sigma_{\square} \\
(\mathrm{kN})\end{array}$ & $\begin{array}{c}V_{M C} \\
(\mathrm{kN})\end{array}$ & $\begin{array}{c}\mathrm{F}_{\text {Det }} \\
(\mathrm{kN})\end{array}$ & $\mu_{\square \square} / \mathrm{F}_{\text {Det }}$ & $\begin{array}{c}\mathrm{F}_{\text {test }} \\
(\mathrm{kN})\end{array}$ & $\mu_{\square \square} / \mathrm{F}_{\text {test }}$ \\
\hline 1 & 17.22 & 0.456 & $2.65 \%$ & 17.49 & 0.98 & 21.82 & 0.79 \\
2 & 22.05 & 0.516 & $2.34 \%$ & 22.31 & 0.99 & 22.43 & 0.98 \\
3 & 16.55 & 0.369 & $2.23 \%$ & 16.99 & 0.97 & 18.65 & 0.89 \\
4 & 17.55 & 0.425 & $2.42 \%$ & 17.84 & 0.98 & 18.17 & 0.97 \\
5 & 16.78 & 0.364 & $2.17 \%$ & 17.18 & 0.98 & 21.95 & 0.76 \\
6 & 12.65 & 0.364 & $2.88 \%$ & 13.05 & 0.97 & 15.61 & 0.81 \\
7 & 15.11 & 0.449 & $2.97 \%$ & 15.76 & 0.96 & 18.41 & 0.82 \\
8 & 15.90 & 0.347 & $2.18 \%$ & 16.76 & 0.95 & 16.34 & 0.97 \\
9 & 16.62 & 0.377 & $2.27 \%$ & 17.37 & 0.96 & 16.95 & 0.98 \\
10 & 37.20 & 0.710 & $1.91 \%$ & 37.56 & 0.99 & 38.77 & 0.96 \\
11 & 45.81 & 0.725 & $1.58 \%$ & 46.78 & 0.98 & 47.30 & 0.97 \\
12 & 33.24 & 0.681 & $2.05 \%$ & 34.84 & 0.95 & 37.55 & 0.89 \\
\hline \multicolumn{7}{c}{ average: } & $2.30 \%$ \\
\hline
\end{tabular}




\section{Reliability of simulated shear walls}

The first order second moment reliability index may be expressed as:

$$
=\frac{\ln \left(R_{m} / Q_{m}\right)}{\sqrt{V_{R}^{2}+V_{Q}^{2}}}
$$

where $R_{m}$ is the mean resistance, $V_{R}$ the Coefficient of Variation $(\mathrm{CoV})$ of the resistance, $Q_{m}$ is the mean demand, and $V_{Q}$ the $\mathrm{CoV}$ of the demand. AISI standards for cold-formed steel design, including the standard that governs cold-formed steel framed shear walls (AISI S400-15) utilize Load and Resistance Factor Design (LRFD) as implemented and detailed in the commentary to AISI S100-16. For LRFD the design strength $\left(\phi R_{n}\right)$ must be greater than any load combinations considered $\left(\Sigma \gamma_{i} Q_{i}\right)$ where $i$ is a summation across various loading types (dead, live, wind, etc.).

$$
R_{n} \quad{ }_{i} Q_{i}
$$

As detailed in[19] the substitution of Eq. (2) into (1) provides different estimates for $\beta$ depending on the load combination selected and on the ratio of the various loads $\left(Q_{i}\right.$ 's) to one another. However, despite this complexity AISI S100-16 has adopted a single load combination and ratio of loads for its LRFD calibration - this results in consistent approximations across different limit states, although it has conceptual limitations as fully discussed in [19]. If we assume the nominal resistance, $R_{n}$, is set equal to the mean resistance from the MC simulations $R_{m}$, and employ the load combinations and load ratios implicit in AISI S100, then the reliability index simplifies to:

$$
=\frac{\ln (1.521 /)}{\sqrt{V_{R}^{2}+0.21^{2}}}
$$

or, for a known $\beta$, the resistance factor may be found as:

$$
=1.521 e^{\sqrt{V_{R}^{2}+0.21^{2}}}
$$

(Note the pre-factor 1.521 may be observed in AISI S100-16 Eq.C-B3.2.2-14[20] ). For this scenario, the $\mathrm{CoV}$ in the resistance drives the reliability assessment. The $\mathrm{CoV}$ in Table 3 provides $V_{R}$ for the 12 simulated walls $\left(V_{M C}\right)$. Currently, AISI S400-15 utilizes a $\phi=0.6$, the $\beta$ implied by this assumption is provided in Table 4 . In addition - the target $\beta$ for AISI standards is 2.5 for members and 3.5 for connections. The $\phi$ that results from these target $\beta$ are also provided in Table 4 . 
Table 4. Reliability index and resistance factor of simulated shear walls

\begin{tabular}{cccc}
\hline $\begin{array}{c}\text { Model } \\
\text { No. }\end{array}$ & $\begin{array}{c}\beta \\
\text { when } \phi=0.6\end{array}$ & $\begin{array}{c}\phi \\
\text { when } \beta=2.5\end{array}$ & $\begin{array}{c}\phi \\
\text { when } \beta=3.5\end{array}$ \\
\hline 1 & 4.39 & 0.896 & 0.725 \\
2 & 4.40 & 0.897 & 0.726 \\
3 & 4.40 & 0.897 & 0.726 \\
4 & 4.40 & 0.897 & 0.726 \\
5 & 4.41 & 0.897 & 0.726 \\
6 & 4.39 & 0.895 & 0.724 \\
7 & 4.39 & 0.895 & 0.724 \\
8 & 4.41 & 0.897 & 0.726 \\
9 & 4.40 & 0.897 & 0.726 \\
10 & 4.41 & 0.898 & 0.727 \\
11 & 4.42 & 0.898 & 0.728 \\
12 & 4.41 & 0.898 & 0.727 \\
\hline mean & 4.40 & 0.90 & 0.73 \\
\hline
\end{tabular}

417 Based on the simulated shear walls the reliability achieved in a design utilizing mean MC

418 simulation results for the nominal strength and the AISI S400-15 $\phi$ factor for shear walls 419 is significantly in excess of target reliabilities (mean $\beta=4.4$ ). If traditional target 420 reliabilities are enforced (2.5 or 3.5) higher $\phi$ factors could be employed. These results cover a limited scope and focus on direct use of the simulation results. In design, simpler methods are usually employed - the following section introduces several potential design methods for CFS-framed OSB-sheathed shear walls, and then assesses their reliability across the 12 selected tests.

\section{Design methods for OSB-sheathed shear walls}

Based on the current design specification and our simulation method, four design methods are proposed below for examination of cold-formed steel shear wall resistance.

Method 1: Current Specification method. In AISI S400-15 (previously AISI S213-12) CFS-framed shear wall strength, with different sheathing types applied, is provided. The method is based on direct experiments (independent from the ones being used here for reliability evaluation) and primarily considers thickness of steel framing, thickness and type of sheathing, and fastener spacing. Wall aspect ratio is also considered for narrow shear walls. Wall strength per unit length of the wall is found directly from a table in AISI S400-15 and multiplied times the actual wall length to arrive at the shear capacity.

Method 2: (Elastic) First fastener failure method. In most structural systems the procedure for conventional design is to perform linear elastic analysis and then scale the results (axial, shear, and moment demands) to the first member and/or connector failure to establish the system strength. Using the fastener-based models developed by Buonoapane et al. [11] and utilized herein, this approach can readily be performed. A linear elastic model of the shear wall is completed, and the results are linearly scaled until the peak fastener demand equals the mean fastener capacity and this is used to establish 
the full shear wall strength. The simulation is linear and deterministic, and provides a

\section{Reliability of design methods against selected tests}

In a traditional LRFD reliability formulation the mean resistance $\left(R_{m}\right)$ is connected to the nominal predicted resistance $\left(R_{n}\right)$ per the following:

$$
R_{m}=P_{m} M_{m} F_{m} R_{n}
$$

where $P, M$, and $F$ are uncorrelated random variables representing bias in the prediction method (i.e., the professional factor, $P$, which is populated by test-to-predicted ratios) as well as bias due to the material properties $(M)$ and fabrication of the structure or connection being considered $(F)$. The subscript $m$ refers to the mean values of $P, M$, and $F$. The $\mathrm{CoV}$ of the resistance, $V_{R}$, is approximated by [20] :

$$
V_{R}=\sqrt{V_{M}^{2}+V_{F}^{2}+V_{P}^{2}}
$$

Where $V_{M}, V_{F}, V_{P}$ are the $\mathrm{CoV}$ of the material, fabrication, and professional factor, respectively. Substituting Eq.'s (2), (5) and (6) into Eq. (1) and again using the load combinations and load ratios implicit in the AISI S100 LRFD calibration, the reliability index may be expressed as:

$$
=\frac{\ln \left(1.521 P_{m} M_{m} F_{m} /\right)}{\sqrt{V_{M}^{2}+V_{F}^{2}+V_{P}^{2}+0.21^{2}}}
$$

The four design methods considered establish four predictions for $P$, i.e. four different mean $\left(P_{m}\right)$ and CoV's $\left(V_{P}\right)$ of test-to-predicted ratios. The remaining random variables $M$ 
and $F$ are considered in two different ways: (a) per the guidance in AISI S100-16 Chapter $\mathrm{K}$, and (b) informed from the MC simulation performed herein. Therefore, for (a) per AISI S100-16 and assuming connections to wood control the strength: $M_{m}=1.0, V_{M}=0.15$, $F_{m}=1.0$, and $V_{F}=0.15$.

In general, the variation in $M$ and $F$ is intended to reflect the inherent variation in material and fabrication quality, independent from the variation in the prediction method. For a CFS-framed OSB-sheathed shear wall this variation is controlled by the OSB-tosteel connection limit state. The MC simulations performed here provide an estimation of the shear wall system variation and per Table 3 the average $V_{M C}=2.3 \%$. Note, the input variability of the peak connector strength has a $\mathrm{CoV}$ of $13 \%$; however, this fastener variability does not result in a high system variability as significant redistribution of load amongst the fasteners occurs. Therefore, for (b) we assume $M_{m}=1.0, F_{m}=1.0 \operatorname{per}[20]$, and $\left(V_{M C}\right)^{2}=\left(V_{M}\right)^{2}+\left(V_{F}\right)^{2}$. The MC simulation provides an estimate of system variability, which in this case is far less than the connection variability - and this will influence the reliability prediction.

The reliability index, $\beta$, at the current AISI S400-15 $\phi$ value for shear walls, and the resulting $\phi$ based on target reliabilities of 2.5 (members) and 3.5 (connections) are provided in Table 5 for the four considered design methods across the two assumptions of system variability.

Table 5 Reliability index and resistance factor across shear wall tests (a) $V_{M}$ and $V_{F}$ per AISI S100-16 connection to wood case

\begin{tabular}{ccccc}
\hline & & $\beta$ & $\phi$ & $\phi$ \\
Design Method & $V_{R}$ & when $\phi=0.6$ & when $\beta=2.5$ & when $\beta=3.5$ \\
\hline AISI S400-15 & 0.24 & 3.60 & 0.86 & 0.62 \\
First Fastener Failure & 0.25 & 4.84 & 1.29 & 0.93 \\
Det. Simulation & 0.23 & 3.24 & 0.76 & 0.55 \\
MC Simulation & 0.23 & 3.33 & 0.78 & 0.57 \\
\hline
\end{tabular}
(b) $V_{M}$ and $V_{F}$ based on MC simulation

\begin{tabular}{ccccc}
\hline Design Method & $V_{R}$ & $\beta$ when $\phi=0.6$ & $\phi$ when $\beta=2.5$ & $\phi$ when $\beta=3.5$ \\
\hline AISI S400-15 & 0.12 & 4.79 & 1.04 & 0.82 \\
First Fastener Failure & 0.14 & 6.32 & 1.57 & 1.22 \\
Det. Simulation & 0.10 & 4.37 & 0.93 & 0.73 \\
MC Simulation & 0.10 & 4.50 & 0.95 & 0.76 \\
\hline
\end{tabular}

The current specification prediction AISI S400-15 is shown to provide a target reliability aligned with a connection limit state (near 3.5) under the typical assumptions for variability (Table 5a). However, if system variability is considered as estimated from the MC simulation, then the connection variability is dampened, and per Table $5 \mathrm{~b}$ current design is conservative and the $\phi$ factor could be increased from 0.6 to 0.82 and still meet the connection target reliability of 3.5. The system effect, in this case, reduces the variability considerably and improves the predicted reliability.

If the fastener-based shear wall model was used to replace the tabled solutions in AISIS400 the reliability would depend on how the model was employed. Traditional engineering design using an elastic model and first predicted fastener failure is unduly 
conservative under any set of assumptions and has limited use in a modern design context. The reliability indices reported in Table 5 indicate deterministic simulation, essentially a shear wall pushover analysis, is adequate - and full MC simulation is not needed. The modest decrease in the mean predicted strength that occurs in the MC simulation is offset by a large and beneficial decrease in variability. This beneficial system effect dominates the reliability calculation.

If deterministic shear wall simulation using the fastener-based model was implemented for design and the beneficial system effect ignored, i.e. Table 5a results, then a $\phi=0.6$, as used in current design, will meet a target reliability of 3.5. If the reduced variability of the shear wall system is accounted for then $\phi$ could be increased to 0.73 for a target reliability of 3.5 or as high as 0.93 for the member target reliability of 2.5. Analysis across a wider series of tests is needed before drawing final conclusions, but this work indicates that the fastener-based simulations can provide comparable reliability to current experimentallybased design methods - and that if system effects on variability are incorporated then $\phi$ factors may be increased above the current value of 0.6 .

\section{8}

539

540

541

542

543

544

545

546

547

548

549

550

551

552

553

554

555

556

557

558

559

560

561

562

563

564

565

\section{Discussion}

Reliability evaluation, as provided in this research, is based on twelve shear wall tests. Analysis of additional shear walls, even within CFS-framed OSB-sheathed configurations, need to be completed before final recommendations for design can be made. Recent fastener testing of Moen et al. [21] provides much needed data on the steelfastener-sheathing shear response for a broader range of conditions and will be needed for any such analyses.

Improvements in the random fastener characterization and in the fastener-based shear wall model also provide avenues for improvement. The random model for the fastener does not consider the potential for differing initial stiffness, this would potentially provide additional system variability and is worth pursuing. The fastener-based shear wall model excludes failures in the studs, tracks, and hold-downs and in the sheathing material outside of the fastener locations. Further, the role of the shear stiffness of the sheathing outside of its impact on the local fastener bearing stiffness is not captured. In addition, sheet-to-sheet edge contact is not considered in the developed models. All of these refinements could further enrich the discussion of the shear wall response and its reliability across multiple potential limit states.

Assessing the reliability for seismic load cases is particularly problematic. For one, the cyclic response of the shear walls must be considered in the reliability analysis. In addition the reliability formulation must be re-considered. Here the issue is avoided by using the reliability formulation utilized in AISI S100 and by considering only the fastener limit state. Meimand and Schafer in [19] provide insight on the impact of seismic load cases on the AISI S100 LRFD calibration (particularly $V_{Q}$ and the pre-factor based on the load combination coefficient and bias). The variations are high and resulting reliability indices are lower than generally assumed for all structural systems. Limit states 
outside of fastener-based damage (e.g. local-global buckling of the chord stud) are possible, but their probability of failure is significantly reduced through the use of capacity-based design principles. Nonetheless, these other limit states are not currently included in the fastener-based simulation, nor in the MC simulations that rely on this model and could be incorporated in the future.

The current state of the art for assessing seismic response is the application of incremental dynamic analysis (IDA). The fastener-based model provided here has been used for driving a series of IDA models of a CFS-framed building ([15,16]). In the FEMA P695 methodology variability in response is assessed by IDA analysis against different earthquake records - but the models are always deterministic. While the assumption that seismic demand variation is much greater than any variation in capacity is generally believed to be true, MC shear wall simulation using IDA could be used to examine the impact of capacity separately from demand. Further, the impact of brittle fastener response may be different in a dynamic analysis than in the nonlinear static analysis and is worth further study.

\section{Conclusions}

Lateral performance of cold-formed steel framed, wood-sheathed, shear walls are dominated by the local response of the sheathing-to-steel connections. This response derives from a complex interaction between the fastener and the sheathing and steel sheet that are connected together and is considered highly variable. A typical shear wall may rely on 100 or more of these connections. Monte Carlo simulations developed and conducted herein indicate that although the connection strength is highly variable sufficient redistribution occurs in shear walls to mitigate this variability and final system shear wall strength is not highly variable. In the cases studied herein the coefficient of variation for individual fastener strength is $13 \%$, while for the system strength the coefficient of variation is predicted to be less than $3 \%$. There are limits to the redistribution amongst the fasteners as mean shear wall strength is modestly reduced (approximately 3\%) below deterministic predictions. In addition, correlation coefficients are used to quantify fastener locations (e.g. near the corners) that are more important than others for determining wall strength. Examination of existing and proposed shear wall design methods indicate that the predicted reduction in variability is a major system benefit when considering reliability. Based on the analysis provided herein the current resistance factor used in the American Iron and Steel Institute standard for cold-formed steel framed shear walls (AISI S400-15) may be excessively conservative. The predicted shear wall reliability index, $\beta$, in this study is 4.8 , against a target of 3.5. Additional analyses are recommended and complications related to seismic reliability discussed, all with a goal of advancing reliability and design for cold-formed steel framed shear walls.

\section{Acknowledgments}

606 
607 This research is supported by National Science Foundation through grants CMMI608 1300484, 1301033 and 1301001. The authors would also like to acknowledge the 609 American Iron and Steel Institute for their support. Any opinions, findings, and 610 conclusions or recommendations expressed in this material are those of the authors and 611 do not necessarily reflect the views of the National Science Foundation or American Iron 612 and Steel Institute.

\section{References}

615 [1] Liu P, Peterman K, Schafer B. Impact of construction details on OSB-sheathed cold616 formed steel framed shear walls. Journal of Constructional Steel Research 2014;101:11461723.

618 [2] Filiatrault A, Folz B. Performance-based seismic design of wood framed buildings. 619 J.Struct.Eng. 2002;128(1):39-47.

620 [3] AISI-S400-15 editor. North American Standard for Seismic Design of Cold-Formed 621 Steel Structural Systems. ; 2015.

622 [4] AISI-S213-07. AISI North American Standard For Cold-Formed Steel Framing 623 Lateral Design. 2007;

624 [5] Serrette R, Encalada J, Juadines M, Nguyen H. Static Racking Behavior of Plywood, 625 OSB, Gypsum, and FiberBond Walls with Metal Framing. Journal of Structural 626 Engineering 1997;123(8).

627 [6] Branston A, Boudreault F, Chen C, Rogers C. Light-gauge steel-frame wood 628 structural panel shear wall design method. Canadian Journal of Civil Engineering 629 2006;33(7):872-89.

630 [7] Zhang H, Rasmussena K, Ellingwood B. Reliability assessment of steel scaffold 631 shoring structures for concrete formwork. Engineering Structures 2012;36.

632 [8] Buonopane S, and Schafer B. Reliability of Steel Frames Designed with Advanced 633 Analysis. Journal of Structural Engineering 2006;132(2).

634 [9] Smith BH, Arwade SR, Schafer BW, Moen CD. Design component and system 635 reliability in a low-rise cold formed steel framed commercial building. Engineering 636 Structures 2016;127:434-46.

637 [10] Chatterjee A, Xiang Y, Moen CD, Arwade SR, Schafer BW. Towards Quantifying 638 Beneficial System Effects In Cold-Formed Steel Wood-Sheathed Floor 
639 Diaphragms 22nd International specialty conference on cold-formed steel structures; 640 November; St Louis, Missouri; 2014.

641 [11] Buonopane SG, Bian G, Tun TH, Schafer BW. Computationally efficient fastener642 based models of cold-formed steel shear walls with wood sheathing. Journal of 643 Constructional Steel Research 2015 7;110(0):137-48.

644 [12] Peterman K, Nakata N, Schafer B. Hysteretic characterization of cold-formed steel 645 stud-to-sheathing connections. Journal of Constructional Steel Research 2014;101:25464664.

647 [13] Seismic Response and Engineering of Cold-formed Steel Framed Buildings. 648 Structures: Elsevier; 2016.

649 [14] Mazzoni S, McKenna F, Scott MH, Fenves GL. Open System for Earthquake 650 Engineering Simulation User Command-Language Manual. 2003;.

651 [15] Leng J, Peterman KD, Bian G, Buonopane GB, Schafer BW. Modeling Seismic 652 Response of a Full-Scale Cold-formed Steel-Framed Building. Engineering Structures 653 Submitted.

654 [16] J. Leng. Simulation of Cold-Formed Steel StructuresJohns Hopkins University; 6552016.

656 [17] Lowes LN, Mitra N, Altoontash A. A beam-column joint model for simulating the 657 earthquake response of reinforced concrete frames. : Pacific Earthquake Engineering 658 Research Center, College of Engineering, University of California; 2003.

659 [18] Vieira LC, Schafer BW. Lateral stiffness and strength of sheathing braced cold660 formed steel stud walls. Eng.Struct. 2012;37:205-13.

661 [19] Meimand V, Schafer B. Impact of load combinations on structural reliability 662 determined from testing cold-formed steel components. Struct.Saf. 2014;48:25-32.

663 [20] AISI-S 100-16. North American Cold-Formed Steel Specification.

664 [21] Moen CD, Tao F, Cole R. Monotonic and cyclic backbone response of single shear 665 cold-formed steel screw-fastened connections. The International Colloquium on Stability 666 and Ductility of Steel Structures; 2016. 